\title{
Use of Omnidirectional Images to Analyze EIderly People's Feelings of Insecurity about Snatch Occurrences on Roads
}

\author{
Joonsang $\mathrm{An}^{* 1}$ and Tetsu Yoshida ${ }^{2}$ \\ ${ }^{1}$ Managing Director, Ga.A Security \& Design, Inc., Japan \\ ${ }^{2}$ Associate Professor, Graduate School of Engineering, Kyoto University, Japan
}

\begin{abstract}
Safety and security are essential to successful, sustainable communities. To build and maintain such communities, research on their safety must be carried out and appropriate policies enacted. In developed countries, the proportion of elderly people is increasing; furthermore, elderly people are easy targets for street crime. Therefore, they might feel insecure, even on safe roads. In this study, in order to understand the road features that people encounter daily that make them feel secure or insecure, authors used omnidirectional images. Authors assessed the percentages of space that different road features (buildings, open spaces, and other road characteristics) occupy in each image and clarified the relationship between these features and elderly people's feelings of security or insecurity in relation to snatch occurrences. The results were as follows: (1) areas with the highest rate of snatch occurrences and feelings of security had the highest percentage of high-rise buildings (4.6\%), all types of buildings (24.2\%), sidewalks (19.2\%), and setbacks $(3.5 \%)$, and the lowest percentages of detached houses $(0.9 \%)$, roads $(4.5 \%)$, and sky $(33 \%)$; and (2) areas with low rates of snatch occurrences and unreasonable feelings of insecurity had no high-rise buildings, high percentages of detached houses ( $9 \%)$, roads (19\%), and sky (44\%), and low percentages of sidewalks $(1.5 \%)$ and setbacks $(0.9 \%)$.
\end{abstract}

Keywords: snatch occurrences; feelings of insecurity toward snatch occurrences; walking environment; elderly people; omnidirectional images

\section{Introduction}

In general, people want to live in a safe and secure community. Thus, considerable research is being carried out and policies enacted so as to build and maintain such communities. Nevertheless, in recent years, particularly in developed countries, many people still feel insecure despite enjoying a high per capita income, high educational levels, high quality health care services, and safe environments overall - thus, a high overall QOL (quality of life). Moreover, the social and economic challenges that population ageing is inflicting on most developed countries are becoming widely recognized. The proportion of elderly people is increasing and along with women, elderly people are perhaps the easiest targets for street crime. Nowadays, more than ever, elderly people and women are not only demanding reduction in crime; they are also in fear of crime. Thus, in the present study, authors focused on elderly people, the streets that they frequent, and their sense of insecurity.

*Contact Author: Joonsang An, Dr. Eng., Managing Director, Ga.A Security \& Design, Inc., Japan

S01, North Bldg. KKVP, 36-1 Goryo Ohara,

Nishikyo-ku, Kyoto, 615-8245 Japan

Tel: +81-75-874-5195 Fax: +81-75-874-5195

E-mail: anjoonsang@gaa-archi.com

(Received October 10, 2012 ; accepted July 23, 2013 )

\subsection{Theories of security}

Currently, there are many theories on what makes people feel secure. Four of the most relevant are: Oscar Newman's "defensible space," C. Ray Jeffery's "crime prevention through environmental design" (CPTED), Ronald V. Clarke's "situational crime prevention," and "environmental criminology." All of these theories are based on the concept of place-based crime prevention planning. "Defensible space" is a term coined by architect Oscar Newman after analyzing the features of residential high-rises. Newman's research (1996) showed that crime and security problems in tall buildings could be reduced when the following conditions are present: natural surveillance, territoriality, and target hardening. Jeffery's CPTED (1971) theory expanded the target area from apartment houses to the planning and design of communities, including commercial and residential areas, schools, etc. CPTED is based on the idea that proper design and effective use of the built environment can lead to a reduction in the incidence and fear of crime, and thus an improvement in residents' QOL. The situational crime prevention theory adopted both the defensible space and CPTED theories. It seeks to reduce opportunities for specific categories of crime by increasing the associated risks and difficulties and reducing the potential rewards. Clarke (1977) identified sixteen opportunity-reducing techniques. More recently, the environmental criminology theory, which is related 
to the work of the Chicago School in the 1920s, focuses on criminal patterns within particular built environments and analyzes the impact of these external variables on people's behavior. In this way, mapping and analysis of crime scenes using GIS (geographic information systems) has made a significant contribution to effective police activities (Richard et al., 2001).

\subsection{Fear of crime}

To successfully achieve a safe and secure society, efforts to reduce crime are essential. It is likewise essential to reduce people's fear of crime. In this study, authors define "fear of crime" as how individuals perceive crime risks and their fear of becoming a victim of some crime. However, individuals do not always feel insecure in places where crime occurs. In addition, paradoxically, even with the presence of elements that prevent crime such as natural surveillance, access control, territoriality, and activity support, feelings of insecurity might not be completely eliminated. Despite the fact that between 1981 and 1991, crime occurrence in the United States steadily declined (Romer et al., 2003) and the same happened in Japan between 2003 and 2011 (Japanese National Police Agency, 2010), fear of crime did not decline much during these periods. Even though the actual likelihood of being a victim is rather small in these countries, fear of crime is spreading even to individuals who have never directly experienced crime (Conklin et al., 1975). Fear of crime also raises mutual distrust between community members (Randy et al., 1989). The routine activity theory (Felson et al., 1995) postulates that a crime takes place upon the convergence in time and space of three elements:

1. A suitable target (victim);

2. Absence of a capable guardian to prevent the crime from happening; and

3. A likely and motivated offender.
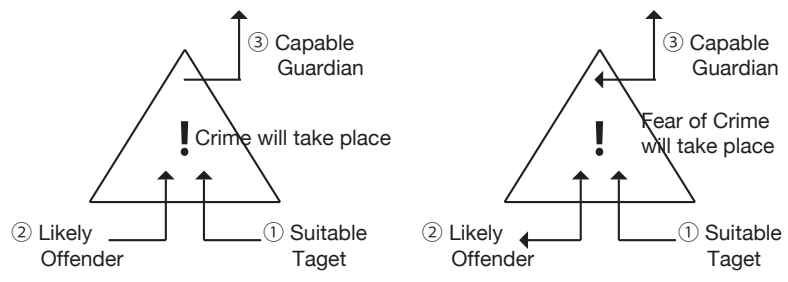

Fig.1. Routine Activity Theory (Left) and Fear of Crime (Right)

However, feelings of insecurity might also emerge when a guardian is present and an offender is not (Fig.1.).

\subsection{Feeling insecure in safe places}

It is appropriate to feel insecure in places where crimes have occurred or where there is a high probability of occurrence (defined as an "unsafe area or road" in this study). In this sense, feelings of insecurity work as a sensor to protect people against becoming victims of a crime. However, this sensor does not always work accurately. If individuals do not feel insecure in unsafe places, they will be in even more danger. Moreover, if individuals feel insecure in places where a crime has never occurred or is less likely to occur (defined as a "safe area or road" in this study), this may lead to mental fatigue. Thus, perceiving safe places as insecure or unsafe places as secure raises individuals' unreasonable feelings of insecurity or security, respectively, and can lead to poor QOL (Anastasia et al., 2006). In contrast, if individuals feel appropriately insecure (secure) in unsafe (safe) places, it means that individuals can perceive the risk properly, thereby enhancing QOL in such places (Fig.2.).

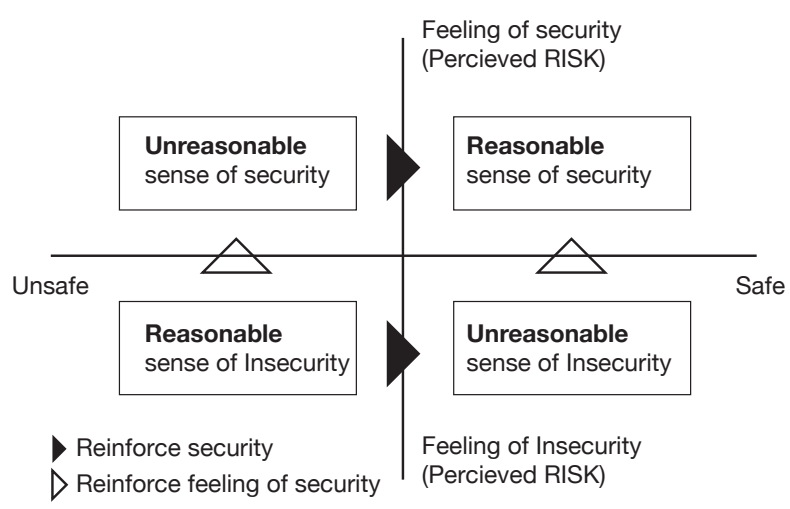

Fig.2. Reinforcing Security and Feelings of Security

\subsection{Purpose}

In our previous study, authors attempted to assess the relationship between snatch occurrences ${ }^{1)}$ and people's reasons for harboring feelings of security or insecurity regarding such occurrences using GIS data, such as road length and width, sidewalks, open spaces, etc ${ }^{2}$. In this study, in order to know which road features make people feel secure or insecure, authors used omnidirectional images ${ }^{3)}$ (i.e., images possessing a $360^{\circ}$ field of view; Point Grey Research, Inc., Ladybug). Authors assessed the percentage of space that different road features (e.g., buildings, open spaces, and other road characteristics) occupy in each image and clarified the relationship between these features and elderly people's feelings of security or insecurity in relation to snatch occurrences. To do this, authors analyzed road features (e.g., the area of walls, windows, or doors) in a target area of Japan.

\section{Literature Review}

Much research has been done on the CPTED theory in environmental criminology. Previous research has focused on the difference between crime and fear of crime, as well as the characteristics of the places where crime occurs.

Some examples of research on the difference between places where crime occurs and places where fear of crime emerges are as follows: Noda et al. (1999) aimed to understand the relationship between pedestrian traffic and pedestrian paths between buildings. They found that low pedestrian traffic was the main reason for harboring feelings of insecurity. Thus, low pedestrian traffic raises fear of crime, even while the risk of crime on such 
roads is low. In addition, Arima et al. (2008) identified the characteristics of crime areas and fear of crime in city centers using crime mapping and spatial analysis. Their main findings were that fear of crime was caused by darkness, poor road visibility, blind alleys, low maintenance, low pedestrian traffic, hardly any views of the residences, and an active imagination. Himura et al. (2008) interviewed female residents of Tokyo between 18 and 59 years of age to clarify the relationship between the location of crime scenes and fear of crime. They found that changing the physical planning of living environments is an effective way for preventing crime. Furthermore, they divided crime into two separate categories: crimes that cause physical damage and crimes that cause material loss. Results were analyzed from the point view of both types of crime and various spatial components. Nagaie et al. $(2007,2008)$ analyzed the relationship between fear of crime and space syntax. Their study presented the possibility of identifying territoriality using axial and isovist maps and how fear of crime was related to high integration and isovist areas. They found that crime often takes place in highly accessible places and that places with high accessibility and numerous isovists increase people's fear of crime. They also concluded that natural surveillance cannot prevent street crime and that the flow of people entering a target area tends to increase fear of crime. Takizawa et al. (2010) investigated the relationship between snatch theft crimes and the spatial attributes of the suburbs of Kyoto City. They found that the mean values of pedestrians, population, and visibility of non-housing sites were relatively high at snatch theft locations. They also found that snatch occurrence areas tended to have relatively high visibility of public facilities. Shimada et $a l$. (2004) examined the cognitive structure and causes of perceived risk and fear of crime among urban residents of Tokyo. They concluded that, generally, incivility and direct or indirect victimization raise fear of crime, and that this relationship is mediated by perceived risk. In addition, incivility directly causes fear of property crime, and this is also mediated by perceived risk; direct victimization has stronger, but similar, effects compared to indirect victimization. Kojima et al. (2009) designed a questionnaire about residents' attitudes toward the safety of their houses and their living environments in order to understand the present condition of these environments. Kojima et al. found that the factor that had the largest effect on the measures taken was not perceived risk or fear, but interest in the environment. An et al. (2011) $)^{2)}$ analyzed the relationship between particular roads and people's feelings of security or insecurity about snatch occurrences on these roads. They found that the longer the road, the more secure individuals felt about it. In addition, individuals felt more secure when roads had sidewalks. Regarding the open space and road length ratio, the smaller the ratio, the more secure individuals felt about the road. In another study, An et al. (2011) assessed the relationship between 50 spatial targets- specifically examining the number of fixation points and fixation duration on space elements - and elderly people's feelings related to snatch occurrences. They found that individuals felt insecure on safe roads (68.8\%) at night (shop windows attracted no gaze, other people attracted gazes of less than $1.2 \mathrm{~s}$, and elevated roads attracted gazes for more than $1.5 \mathrm{~s}$ ), secure on unsafe roads $(39.3 \%)$ at daytime (standing signboards attracted gaze no more than once; total movements of fixation attracted gaze more than 153.3 times; roads attracted gazes no more than twice; and walkup buildings never attracted gaze).

However, unlike these previous studies, the present study focused on the relationship between crime occurrence and elderly people's feelings of security or insecurity concerning snatch theft through correspondence analysis. Authors also analyzed the features of the roads in a target area using data collected through omnidirectional images.

\section{Data Collection and Description 3.1 Data collection}

In this study, authors use three types of data: crime (snatch) occurrences obtained from the police department (3.1.1), feelings of security or insecurity toward snatch occurrences obtained through interviews (3.1.2), and omnidirectional images obtained using a $360^{\circ}$ camera (3.1.3). More detailed descriptions are as follows.

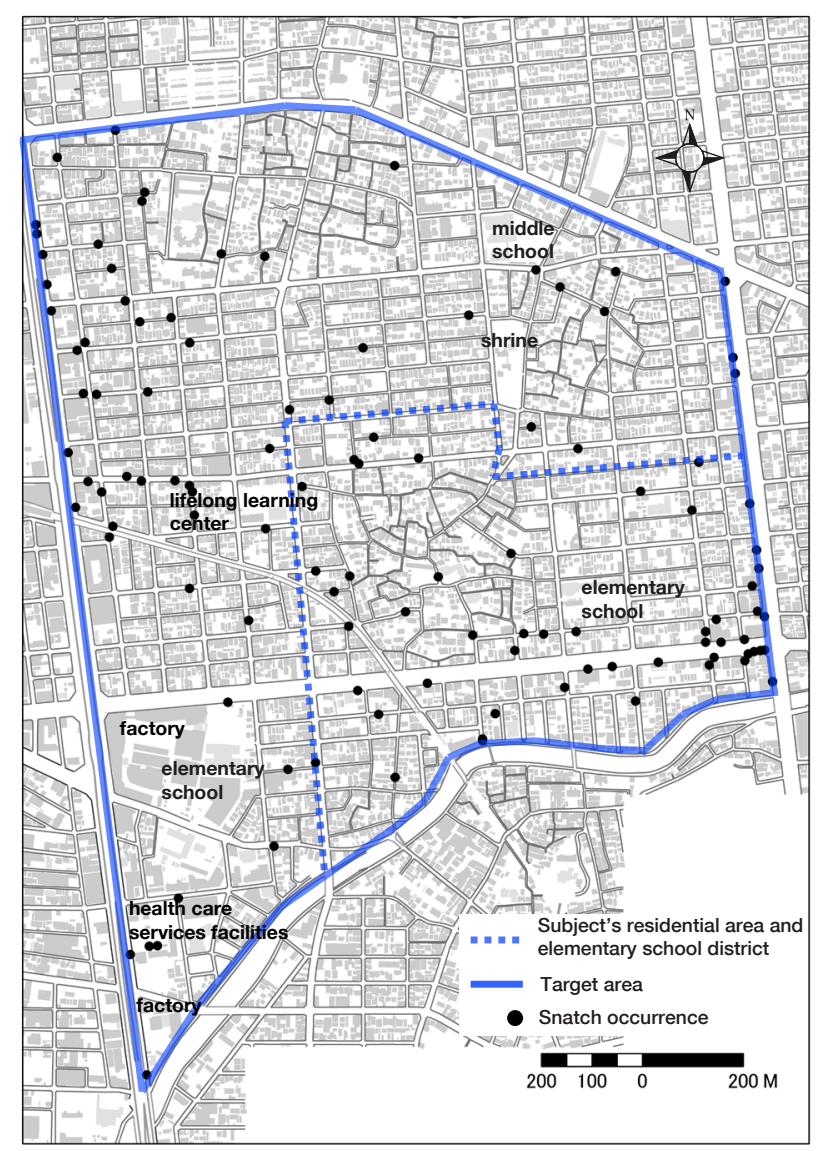

Fig.3. Target Area 


\subsubsection{Crime (snatch) occurrence}

Snatch occurrence data were obtained from the police department. They consist of 112 cases of snatch theft that occurred between January 2003 and October 2008. These cases were grouped according to the place of occurrence - that is, those occurring on the same road - giving a total of 100 cases.

\subsubsection{Feelings of security/insecurity concerning snatch theft}

These data were collected from 121 elderly people (all older than 60 years of age) who were interviewed from January 15 through 19, 2009. The interviewees resided in an area located $7 \mathrm{~km}$ from the center of the studied prefecture in Japan, which is characterized by having 988 roads. More than $26 \%$ of the residents of that area are older than 65 years of age. This area was deliberately selected to achieve a better understanding of elderly people's feelings of insecurity or security in an area with numerous roads possessing similar characteristics; that is, roads with high snatch occurrence rates and coexisting straight and curved roads (Fig.3.).

\subsubsection{Omnidirectional images}

\section{1) Camera installation}

The $360^{\circ}$ camera was placed on the roof of a vehicle on a support device located $1700 \mathrm{~mm}$ high. The camera was controlled by a laptop from inside the vehicle where the collected data was saved (Fig.4.).

2) Determining shooting spots

Of the 988 roads, authors collected more than 10 responses from participants for 83 of them in this research (Fig.5.). Authors set the camera range (recognizable images) to be $20 \mathrm{~m}$. Images were taken at the following spots on a given road: $20 \mathrm{~m}$ from the beginning of the road (starting point), $20 \mathrm{~m}$ from the end of the road (end point), and at a middle point located between the latter two points (middle point). This means

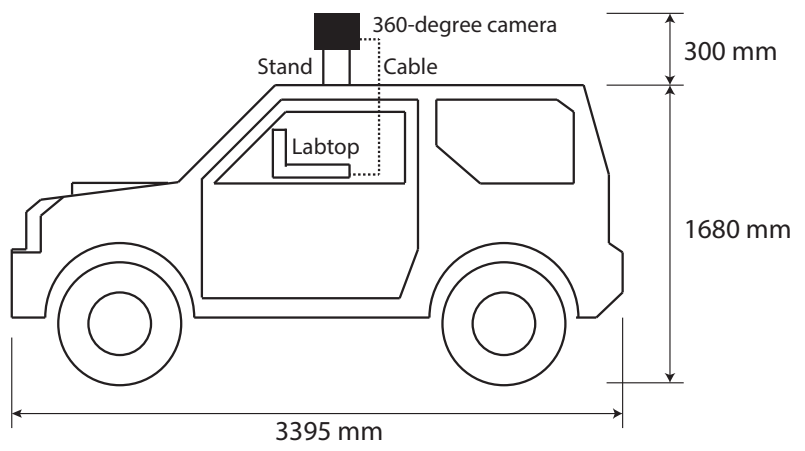

Fig.4. Camera Installation on the Vehicle

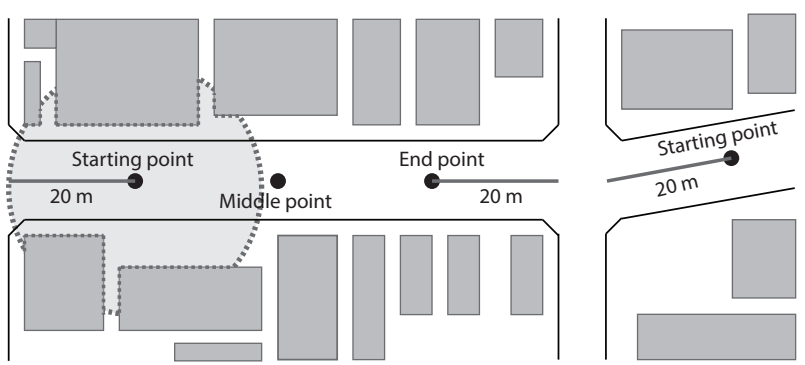

Fig.6. Shooting Spots

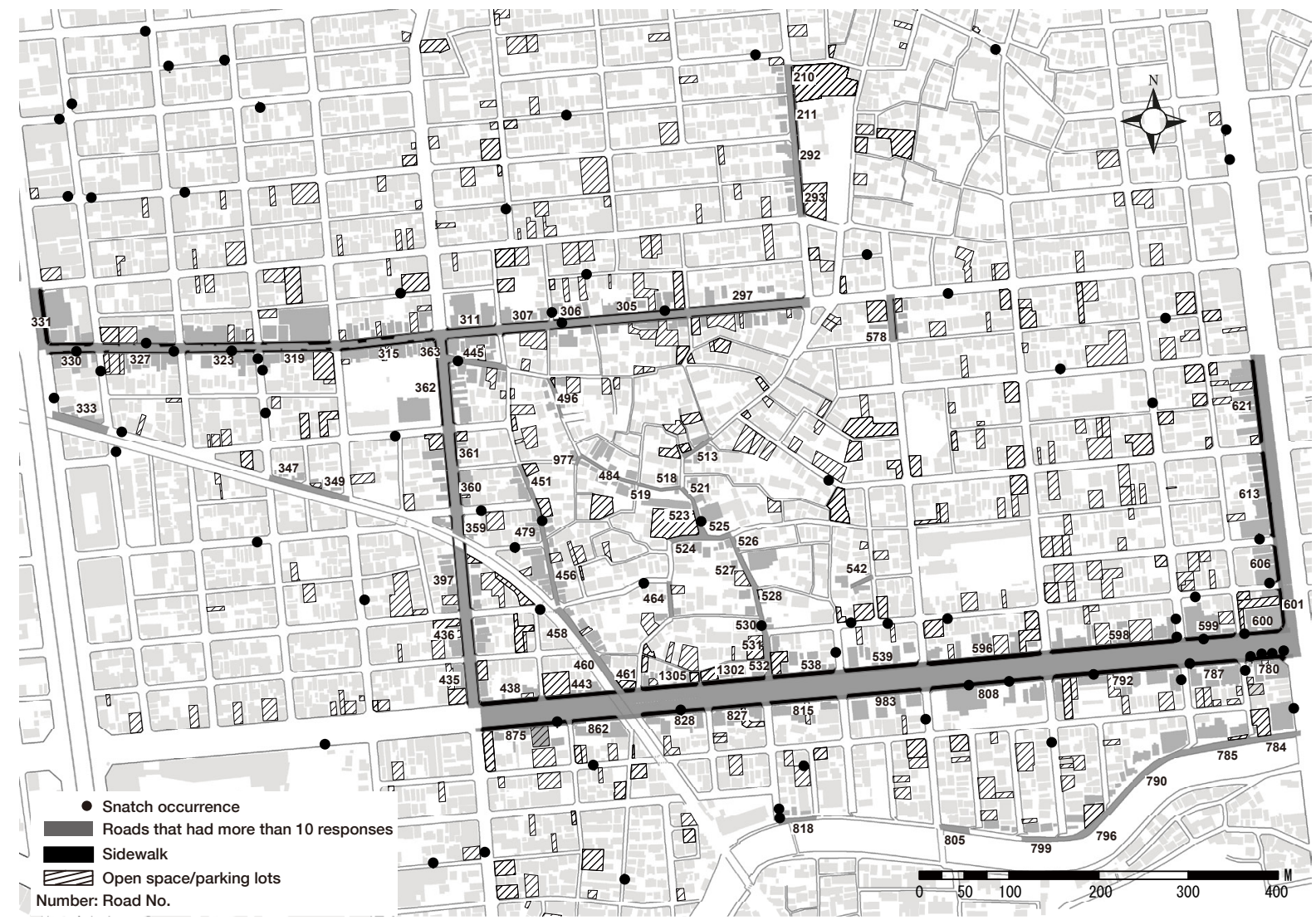

Fig.5. Distribution of Roads for which more than Ten Participants Responded were Collected 
that the covered area for every road was $120 \mathrm{~m}$. For longer roads, authors determined four shooting spots instead of three; only five roads matched this description. Of the 83 roads, 254 images were obtained. (Fig.6.).

\subsection{Extraction of road features from the omnidirectional images}

\subsubsection{Classification of road features}

Road features were classified into three main categories: buildings, roads, and open spaces and nature. These, as shown in Table 1., were subsequently broken down into 28 sub-categories of features that are easily recognizable from the street.

Table 1. Road Characteristic Classification

\begin{tabular}{|c|c|c|c|c|}
\hline Categories & Sub-Categories & $\% *$ & Sub-Categories & $\% *$ \\
\hline \multirow[t]{8}{*}{ Buildings } & Detached house** & 5.7 & Opening (doors, & 1.4 \\
\hline & Store** & 3.8 & windows) & \\
\hline & Apartment** & 3.1 & Hedges & 2.7 \\
\hline & Factory** & 0.3 & Sign boards & 0.6 \\
\hline & Public facility** & 0.2 & $\begin{array}{l}\text { Garden-shrub in a } \\
\text { building site }\end{array}$ & 3.3 \\
\hline & Walkup building** & 1.8 & $\begin{array}{l}\text { Parking lot } \\
\text { (personal) }\end{array}$ & 1.7 \\
\hline & $\begin{array}{l}\text { High-rise } \\
\text { building** }\end{array}$ & 1.5 & Petback $^{5}$ & 1.4 \\
\hline & $\begin{array}{l}\text { Unidentified } \\
\text { building4)** }\end{array}$ & 1.9 & Garden & 1.1 \\
\hline \multirow[t]{4}{*}{ Roads } & High level road & 1.5 & Guardrail & 0.6 \\
\hline & Roads & 14.6 & Telephone poles & 0.7 \\
\hline & Sidewalks & 8.5 & Trees lining a street & 2.6 \\
\hline & & & Shrubbery & 0.8 \\
\hline \multirow{3}{*}{$\begin{array}{c}\text { Open } \\
\text { spaces and } \\
\text { nature }\end{array}$} & Park & 0.1 & Sky ${ }^{6}$ & 38.9 \\
\hline & Open space & 0.3 & River & 0.5 \\
\hline & $\begin{array}{l}\text { Parking lot } \\
\text { (commercial) }\end{array}$ & 0.3 & Embankment & 0.2 \\
\hline
\end{tabular}

*Average percentage that each sub-category occupies in the 254 omnidirectional images on the 83 roads. All the categories add up to $100 \%$.

** Refers to only walls without the openings.

\subsubsection{Extraction of road features}

Authors then determined the percentage of space that each road feature occupied in each image (out of 100\%). Fig.7. shows the omnidirectional image on top while the lower image shows the road features identified in different colors ${ }^{7)}$.
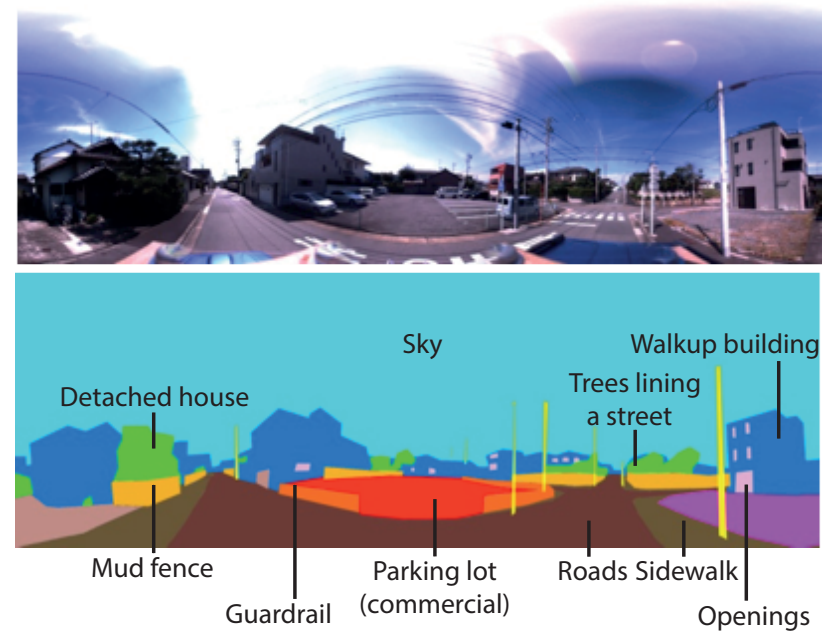

Fig.7. Extraction of Road Features from Omnidirectional Images

\subsubsection{Classification of road features}

As shown in Table 1., the feature with the highest percentage of exposure in the omnidirectional images (254 images) was the sky, at 38.9\%. This is followed by all the types of buildings merged together (without considering openings, hedges, sign boards, gardens or shrubs, parking lots, and setbacks), at $18.3 \%$. Then, roads and sidewalks occupy $14.6 \%$ and $8.5 \%$ of the images, respectively.

\section{Correspondence Analysis}

As in our previous paper ${ }^{2}$, in this study authors used correspondence analysis to create simple twoway and multi-way tables containing some measure of correspondence between rows and columns. Fig.8. shows that there are 28 reasons for harboring feelings of insecurity or security concerning snatch occurrences on each road (83 roads), and a total of 2,324 rows. In this paper, authors use a table that presents the roads (83) and reasons for secure (12 reasons) and insecure feelings (16 reasons) toward snatch occurrences. This paper used the following settings (Table 2.).

Table 2. Correspondence Analysis Settings

\begin{tabular}{c|c}
\hline Table & Roads (83) By Reasons (28) \\
Dimensions & 2 \\
Measure & CHISQ \\
Standardization & RCMEAN \\
Normalization & SYMMETRIAL \\
\hline
\end{tabular}

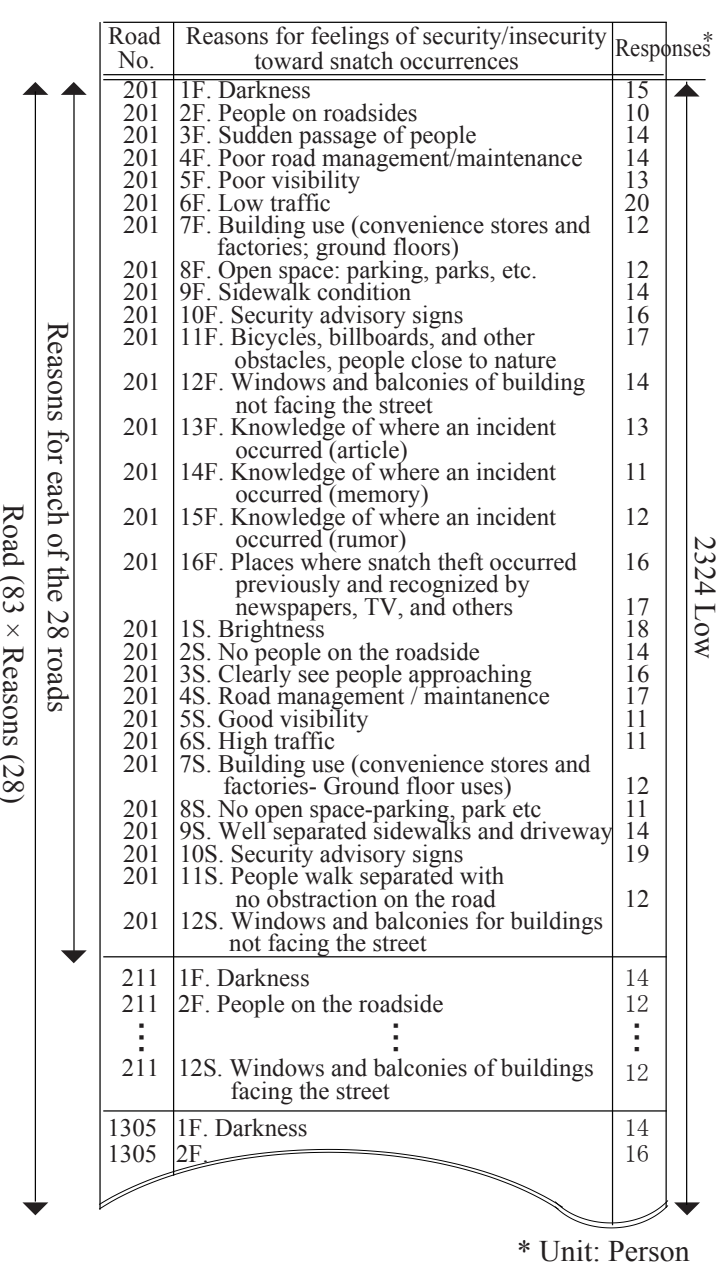

Fig.8. Cross-Tabulation Table 


\section{Results}

A correspondence map displays two dimensions that emerge from the principal component analysis of point distances. The points are displayed in relation to these dimensions. The correspondence analysis helped us obtain the coordinates (Fig.9.), which were then used in a k-means clustering method; thus, 10 groups were classified, as shown in Table 3.

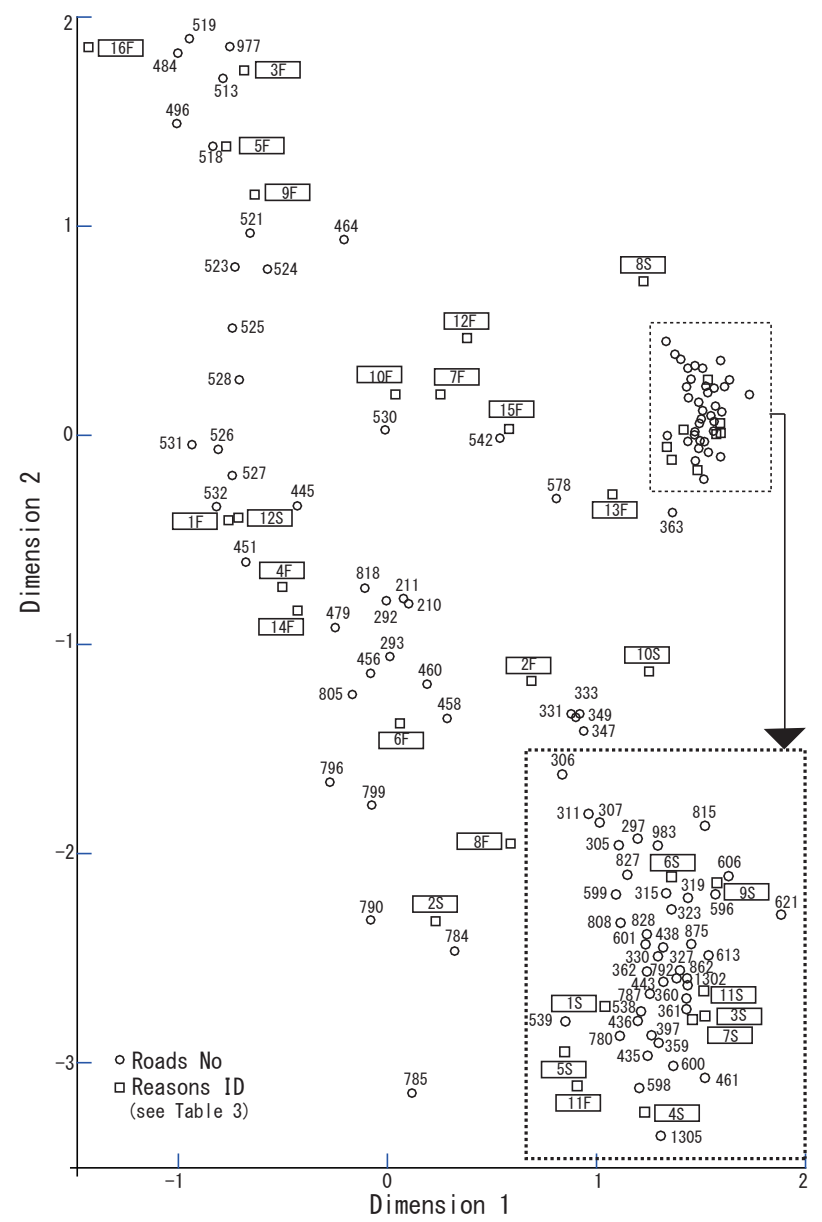

Fig.9. Row and Column Points, Symmetric Normalization

\subsection{Snatch occurrences and reasons for feelings of insecurity or security}

Snatch theft episodes occurred in only $9.9 \%(100)$ of all the roads analyzed in this area (988). The rate of snatch occurrences on the 83 roads from which authors received more than 10 responses was $26.5 \%$ (22 cases). Interesting results emerged from Groups 2, 4, and 5. In Group 2, the snatch occurrence was $45.2 \%$ (14 cases), but the respondents reported the highest number of reasons for feeling secure on these roads. In Groups 4 and 5 , the snatch occurrence was $12.5 \%$ (one case) and $8.3 \%$ (one case), respectively. However, the respondents stated five reasons for feeling insecure. In Groups 1, 3 , and 8 , there were a similar number of reasons for feeling insecure and for feeling secure. Group 6 had only one road (which was unsafe) but three reasons for feeling insecure. Group 9 had only two roads, but the respondents felt secure on the safe roads (Table 3.).
Table 3. Reasons for Feelings of Security/Insecurity

\begin{tabular}{|c|c|c|}
\hline Group & $\begin{array}{l}\text { Reasons for feelings of security/insecurity } \\
\text { toward snatch occurrences (responses) }\end{array}$ & $\begin{array}{l}\text { S/Roads } \\
(\%)^{*}\end{array}$ \\
\hline 1 & $\begin{array}{l}\text { 1S: Brightness (358) } \\
\text { 5S: Good visibility (138) } \\
\text { 4F: Poor road management/maintenance (2) } \\
\text { 11F: Bicycles, billboards, and other obstacles, } \\
\text { people close to nature (30) } \\
\text { 13F: Knowledge of where an incident } \\
\text { occurred (article) (22) } \\
\text { 15F: Knowledge of where an incident } \\
\text { occurred (rumor) (32) }\end{array}$ & $\begin{array}{c}3 / 14 \\
(21.4)\end{array}$ \\
\hline 2 & $\begin{array}{l}\text { 3S: Clearly see people approaching (184) } \\
\text { 9S: Well separated sidewalks and driveway } \\
\text { (323) } \\
\text { 11S: People walk separated with no } \\
\text { obstruction on the road (139) }\end{array}$ & $\begin{array}{l}14 / 31 \\
(45.2)\end{array}$ \\
\hline 3 & $\begin{array}{l}\text { 1F: Darkness (163) } \\
\text { 12S: Windows and balconies of buildings } \\
\text { facing the street ( } 7)\end{array}$ & $\begin{array}{l}14 / 31 \\
(45.2)\end{array}$ \\
\hline 4 & $\begin{array}{l}\text { 3F: Sudden passage of people (40) } \\
\text { 5F: Poor visibility (79) } \\
\text { 9F: Sidewalk condition (88) }\end{array}$ & $\begin{array}{c}1 / 8 \\
(12.5)\end{array}$ \\
\hline 5 & $\begin{array}{l}\text { 6F: Low traffic (105) } \\
\text { 14F: Knowledge of where an incident } \\
\text { occurred (memory) (11) }\end{array}$ & $\begin{array}{l}1 / 12 \\
(8.3)\end{array}$ \\
\hline 6 & $\begin{array}{l}\text { 7F: Building use (convenience stores and } \\
\text { factories; ground floors) (32) } \\
\text { 10F: Security advisory signs (15) } \\
\text { 12F: Windows and balconies for buildings } \\
\text { not facing the street (18) }\end{array}$ & $\begin{array}{c}1 / 1 \\
(100)\end{array}$ \\
\hline 7 & - & $0 / 1(0)$ \\
\hline 8 & $\begin{array}{l}\text { 2F: People on roadsides (106) } \\
\text { 8F: Open space: parking, parks, etc. (5) } \\
\text { 10S: Security advisory signs (37) }\end{array}$ & $1 / 4(25)$ \\
\hline 9 & 2S: No people on the roadside (29) & $0 / 2(0)$ \\
\hline 10 & $\begin{array}{l}\text { 16F: Places where snatch theft occurred } \\
\text { previously and recognized by newspapers, } \\
\text { TV, and others (1) }\end{array}$ & $0 / 3(0)$ \\
\hline
\end{tabular}

Table 4. High-rise Buildings and Detached Houses

\begin{tabular}{ccccl}
\hline Group & $\begin{array}{c}\text { High-rise } \\
\text { building }(\%)\end{array}$ & $\begin{array}{c}\text { Detached } \\
\text { house }(\%)\end{array}$ & $\begin{array}{c}\text { Building } \\
(\%)\end{array}$ & $\begin{array}{l}\text { S/Roads } \\
(\%) *\end{array}$ \\
\hline 1 & 0.9 & 5.1 & 19.7 & $3 / 14(21.4)$ \\
2 & 4.6 & 0.9 & 24.2 & $14 / 31(45.2)$ \\
3 & 0.7 & 7.7 & 15.2 & $14 / 31(45.2)$ \\
4 & 0 & 10.6 & 16.5 & $1 / 8(12.5)$ \\
5 & 0 & 8.1 & 13.8 & $1 / 12(8.3)$ \\
6 & 0 & 4.5 & 18.6 & $1 / 1(100)$ \\
7 & 1.2 & 1 & 16.2 & $0 / 1(0)$ \\
8 & 0.1 & 5.2 & 12.3 & $1 / 4(25)$ \\
9 & 3.4 & 2.5 & 24.6 & $0 / 2(0)$ \\
10 & 0 & 11.2 & 14.9 & $0 / 3(0)$ \\
\hline Average for & 1.5 & 5.7 & 13.8 & $22 / 83(26.5)$ \\
each road & \multicolumn{5}{c}{} \\
\hline \multicolumn{5}{c}{ *S/Roads: snatch occurrence /total number of roads }
\end{tabular}

\subsection{Classification of roads and road features}

\subsubsection{High-rise buildings and detached houses}

All the buildings together occupied $13.8 \%$ of the omnidirectional images. Of all groups, Group 2, which had a high rate of snatch occurrences and a high feeling 
of security, had the highest percentage of high-rise buildings in its images (4.6\%). In contrast, Groups 4 and 5, which had low rates of snatch occurrences and high feelings of insecurity, did not have any high-rise buildings. Group 2 showed the highest percentage of all types of buildings $(24.2 \%)$ and the lowest percentage of detached houses $(0.9 \%)$. In contrast, groups 4 and 5 showed the highest percentage of detached houses among all groups (10.6\% and 8.1\%, respectively; Table 4.).

\subsubsection{Roads and sidewalks}

Group 2 had the lowest percentage of roads in the images $(4.5 \%)$. In a previous study, this group had the longest $(85 \mathrm{~m})$ and widest $(14.4 \mathrm{~m})$ roads among all groups. ${ }^{2)}$ Group 2 also had the highest percentage of sidewalks $(19.2 \%)$. The percentages of roads present in Groups 4 and 5 (18.7\% and 19.6\%, respectively) were higher than the group average of $14.6 \%$. In contrast, the percentages of sidewalks in these groups $(0 \%$ and $2.5 \%$, respectively) were lower than the group average of $8.5 \%$ (Table 5 .).

Table 5. Roads and Sidewalks

\begin{tabular}{clll}
\hline Group & Road (\%) & Sidewalk (\%) & S/Roads (\%)* \\
\hline 1 & 13.1 & 13.8 & $3 / 14(21.4)$ \\
2 & 4.5 & 19.2 & $14 / 31(45.2)$ \\
3 & 18.1 & 4.9 & $14 / 31(45.2)$ \\
4 & 18.7 & 0 & $1 / 8(12.5)$ \\
5 & 19.6 & 2.5 & $1 / 12(8.3)$ \\
6 & 21.1 & 0 & $1 / 1(100)$ \\
7 & 19.8 & 0 & $0 / 1(0)$ \\
8 & 26.7 & 1.6 & $1 / 4(25)$ \\
9 & 11.6 & 7.1 & $0 / 2(0)$ \\
10 & 15.7 & 1.9 & $0 / 3(0)$ \\
\hline Average for & 14.6 & 8.5 & $22 / 83(26.5)$ \\
each road & & \multicolumn{3}{c}{} \\
\hline \multicolumn{5}{c}{ *S/Roads: snatch occurrence/total number of roads }
\end{tabular}

\subsubsection{Setbacks}

Group 2 had the highest percentage of setbacks in the images $(3.5 \%)$. Setback percentages in groups 4 and $5(1 \%$ and $0.7 \%$, respectively) were lower than the group average of $1.4 \%$ (Table 6. .).

Table 6. Setbacks

\begin{tabular}{ccl}
\hline Group & Setback $(\%)$ & S/Roads $(\%)^{*}$ \\
\hline 1 & 1.4 & $3 / 14(21.4)$ \\
2 & 3.5 & $14 / 31(45.2)$ \\
3 & 0.4 & $14 / 31(45.2)$ \\
4 & 1 & $1 / 8(12.5)$ \\
5 & 0.7 & $1 / 12(8.3)$ \\
6 & 0.1 & $1 / 1(100)$ \\
7 & 0 & $0 / 1(0)$ \\
8 & 0.9 & $1 / 4(25)$ \\
9 & 0 & $0 / 2(0)$ \\
10 & 0.7 & $0 / 3(0)$ \\
\hline Average for each & 1.4 & $22 / 83(26.5)$ \\
road & & \\
\hline *S/Roads: snatch occurrence /total number of roads
\end{tabular}

\subsubsection{Sky}

Sky was the road feature with the highest percentage of exposure in the omnidirectional images. Group 2 had the lowest percentage of sky in its images (33\%). The percentages of sky in Groups 4 and 5 (45.8\% and $43.3 \%$, respectively) were higher than the group average of $38.9 \%$ (Table 7 .).

\begin{tabular}{ccl} 
Table 7. Sky & & \\
\hline Group & Sky $(\%)$ & S/Roads $(\%)^{*}$ \\
\hline 1 & 38.7 & $3 / 14(21.4)$ \\
2 & 33 & $14 / 31(45.2)$ \\
3 & 34.6 & $14 / 31(45.2)$ \\
4 & 45.8 & $1 / 8(12.5)$ \\
5 & 43.3 & $1 / 12(8.3)$ \\
6 & 39.2 & $1 / 1(100)$ \\
7 & 47.1 & $0 / 1(0)$ \\
8 & 35.6 & $1 / 4(25)$ \\
9 & 44.9 & $0 / 2(0)$ \\
10 & 41.6 & $0 / 3(0)$ \\
\hline Average for & 38.9 & $22 / 83(26.5)$ \\
each road & \multirow{2}{*}{$*$ S/Roads: snatch occurrence /total number of roads }
\end{tabular}

\section{Implications and Conclusion}

In this study, authors used correspondence analysis to assess the relationship between road features and elderly people's reasons for harboring feelings of security or insecurity in relation to snatch occurrences. Following this, authors analyzed the features of the roads in a target area, which authors divided into 10 groups through the k-means clustering method. The results can be summarized as follows:

(1) Group 2 had the highest rate of snatch occurrences $(45.2 \%)$ but also the highest feelings of security due to a clear view of approaching people; high traffic roads; good use of buildings; no open spaces such as parking lots or parks; well separated sidewalks and driveway; and people walk separated with no obstruction on the road. This implies that individuals can feel an unreasonable sense of security on unsafe roads. In the images, Group 2 had the highest percentage of high-rise buildings (4.6\%), all types of buildings $(24.2 \%)$, sidewalks $(19.2 \%)$, and setbacks $(3.5 \%)$, and the lowest percentage of detached houses (0.9\%), roads (4.5\%), and sky (33\%; Fig. 10 .).

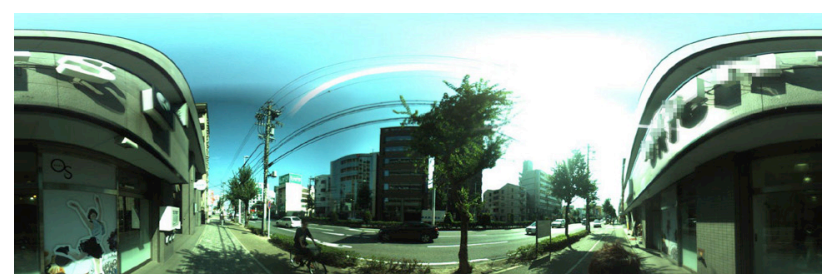

Fig.10. An Omnidirectional Sample Image of Group 2

(2) Groups 4 and 5 had low rates of snatch occurrences (12.5\% and 8.3\%, respectively); however, individuals harbored an unreasonable sense of insecurity on these safe roads due to the irregular occurrence of passersby, poor visibility, low traffic roads, poor sidewalk conditions, and knowledge of incidents that had occurred in that area from memory. 
In the images, these groups did not show any highrise buildings, had the highest percentage of detached houses $(10.6 \%$ and $8.1 \%$, respectively), a percentage of roads $(18.7 \%$ and $19.6 \%$, respectively) higher than the group average, a percentage of sidewalks $(0 \%$ and $2.5 \%$, respectively) lower than the group average, a percentage of setbacks ( $1 \%$ and $0.7 \%$, respectively) lower than the group average, and a percentage of sky ( $45.8 \%$ and $43.3 \%$, respectively) much higher than the group average (Fig.11.).

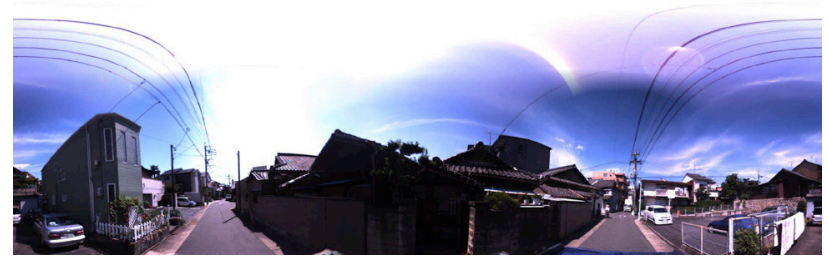

Fig.11. An Omnidirectional Sample Image of Groups 4 and 5

The main conclusion of this study is that there is a clear lack of correspondence between the objective security of the studied roads and elderly people's sense of security. When people feel secure on unsafe roads, these roads appear to show, in general, the following characteristics: a high percentage of highrise buildings, sidewalks, and setbacks, and a low percentage of detached houses, roads, and sky in the field of view; these fit the characteristics of roads that are wide and straight. Conversely, when people feel unreasonably insecure on otherwise safe roads, the roads will likely not have any high-rise buildings, have a high percentage of detached houses, roads, and sky, and have a low percentage of sidewalks and setbacks in the field of view; these characteristics appear to describe roads that are mainly narrow and curved.

\section{Acknowledgments}

We appreciate the cooperation of the 121 subjects, the safety division of the police, and residential associations. This research was supported by a Grantin-Aid for Scientific Research (B) of the Japan Society for the Promotion of Science, 2008-2010.

\section{Notes}

1) Theft of handbag or personal effect on the street.

2) Reference AN et al. (2011) Reference 2).

3) In order to understand what road features make people feel secure or insecure, authors used a spherical digital video camera. This camera covers fields of view of up to $360^{\circ}$ (including the sky) without stitching images. Authors think that omnidirectional images are a good way to extract surrounding road features even though this camera produces a distortion in straight lines, which might look different from the real environment.

4) Buildings were located at a certain distance from the camera so that they could not be recognized; therefore, authors were unable to categorize them.

5) The area located between the sidewalk or road and the buildings.

6) Vault space.

7) Authors measured the colored areas by using image-processing software; after defining the desired areas, authors colored each differently. Measurement data was recorded in the measurement log panel. With these data, authors were able to determine the percentage of space that each road feature occupied in each image.

\section{References}

1) An Joonsang, YOSHIDA Tetsu (2011) Relationship between space elements of eye fixation tendency and feelings of insecurity of the elderly toward snatch occurrences. Journal of architecture and planning, Vol. 76, No. 667, pp.1577-1584.

2) An Joonsang, YOSHIDA Tetsu (2011) Use of Correspondence Analysis to Analyze the Feelings of Insecurity of the Elderly toward Snatch Occurrences on Roads. Journal of Asian Architecture and Building engineering, Vol. 10, No. 1, pp.179-186.

3) Anastasia Loukaitou-Siders. (2006) Is it Safe to Walk? Neighborhood Safety and Security Considerations and Their Effect on Walking. Journal of Literature, Vol. 20, No. 3, pp.119-132.

4) Conklin, J.E. (1975) The Impact of Crime. New York. Macmillan.

5) Felson, Marcus (1995) Crime and Everyday Second edition, Thousand Oaks, CA: Pine Forge Press.

6) Japanese National Police Agency. (2010) crime situation 2010. http://www.npa.go.jp/toukei/index.htm

7) Jeffrey, C. Ray. (1971) Crime Prevention Through Environmental Design. Sage Publications.

8) Kojima Takaya, Wakabayashi Naoko, Nakatamaya Miho, Hino Kimihiro (2009) Causality analysis for residents' attitude on safety of their houses and living environment. Architectural Institute of Japan, No. 7, pp.104-109.

9) Kyoichi Himura, Haruko Iimura, Osamu Koide (2004) Analysis on the result of the survey about the location of crime Scene and the fear of crime at a urban space. Reports of the City Planning Institute of Japan, No. 2, pp.45-49.

10) Nagaie Tadashi, Hokao Kazunori, Inohae Takuro (2007) Analysis of Surveillance and Territoriality on CPTED and relation for the fear of crime: Based on Axial line and Isovist on Space syntax theory. City planning review, Special issue, Papers on city planning, No. 42, pp.505-510.

11) Nagaie Tadashi, Hokao Kazunori, Inohae Takuro (2008) Analysis of the relationships between the accessibility of urban space based on the Space Syntax Theory and the opportunity crime, the police's perceived risk of crime. City planning review, Special issue, Papers on city planning, No. 43, pp.43-48.

12) Nagayaichi Kazuya. (2006) Risk no monosashi. NHK Publishing Co., Ltd.: Endo kenichi.

13) Newman, O. (1996) Creating Defensible Space. Crime prevention through urban design.

14) NODA Daisuke, MUROSAKI Yoshiteru, TAKAMATSU Takachika (1999) A Study on Crime Prevention through Environmental Design - The Relation between Crime and the Elements of Streets and Paths for Pedestrians in the City -. City planning review, Special issue, Papers on city planning, No. 34, pp.781-786.

15) Randy L. Lagrange, Kenneth F. Ferraro. (1989) ASSESSING AGE AND GENDER DIFFERENCES IN PERCEIVED RISK AND FEAR OF CRIME. Criminology, Vol. 27, Issue 4, pp.697-720.

16) Richard H. Schneider, Ted Kitchen (2001) Planning for Crime Prevention. A Transatlantic Perspective. Routledge.

17) Romer, D., Jamieson, K. H. and Aday, S. (2003) Television news and the cultivation of fear of crime. Journal of Communication, Vol. 53, Issue 1, pp.88-104.

18) Ronald, V. (1977) Situational Crime Prevention. Successful case studies second edition. Harrow and Heston.

19) Shimada Takahito, Suzuki Mamoru, Harada Yutaka (2004) Fear of crime and perceived risk: The causes and structures (Rising Fear of Crime and Re-building Safe Society in Japan: Moral Panic or Evidence-Based Crime Control). Japanese association sociological Criminology, No. 29, pp.51-64.

20) Takafumi ARIMA, Kazunari SUGIMURA (2008) Spatial analysis of relationship between crime and fear of crime. Proc.6thInt. Sympo. On City plann. And Environ. Management in Asia Country, pp.273-284.

21) Takizawa Atushi, Wonyong Koo, Naoki Katoh (2010) Discovering Distinctive Spatial Patterns of Snatch Theft in Kyoto City with CAEP. Journal of Asian Architecture and Building engineering, Vol. 9, No. 1, pp.103-110. 